\title{
Author Correction: A transcriptomic analysis of the phylum Nematoda
}

John Parkinson, Makedonka Mitreva, Claire Whitton, Marian Thomson, Jennifer Daub, John Martin, Ralf Schmid, Neil Hall, Bart Barrell, Robert H. Waterston, James P. McCarter and Mark L. Blaxter

Correction to: Nature Genetics https://doi.org/10.1038/ng1472, published online 14 November 2004.

In the version of this article initially published, in Supplementary Methods Table 2, 'Kapulkin, Vadim' should have read 'Kapulkin, Wadim?

Published online: 15 June 2020

https://doi.org/10.1038/s41588-020-0658-6

(C) The Author(s), under exclusive licence to Springer Nature America, Inc. 2020

\section{Publisher Correction: Mendelian randomization accounting for correlated and uncorrelated pleiotropic effects using genome-wide summary statistics}

Jean Morrison (D), Nicholas Knoblauch, Joseph H. Marcus (D), Matthew Stephens (D) and Xin He (D)

Correction to: Nature Genetics https://doi.org/10.1038/s41588-020-0631-4, published online 25 May 2020.

In the version of this article initially published, Table 1 was omitted from the PDF version but was present in the HTML version. In addition, reference 4 incorrectly cited Zhang, G. et al. Genetic associations with gestational duration and spontaneous preterm birth. N. Engl. J. Med. 377, 1156-1167 (2017); Zheng, J. et al. Recent developments in Mendelian randomization studies. Curr. Epidemiol. Rep. 4, 330-345 (2017) is the correct reference. Finally, some labels indicating high versus low power in the second and fourth graphs in Fig. 2c were switched. The errors have been corrected in the HTML and PDF versions of the article.

Published online: 29 May 2020

https://doi.org/10.1038/s41588-020-0655-9

(c) The Author(s), under exclusive licence to Springer Nature America, Inc. 2020 